
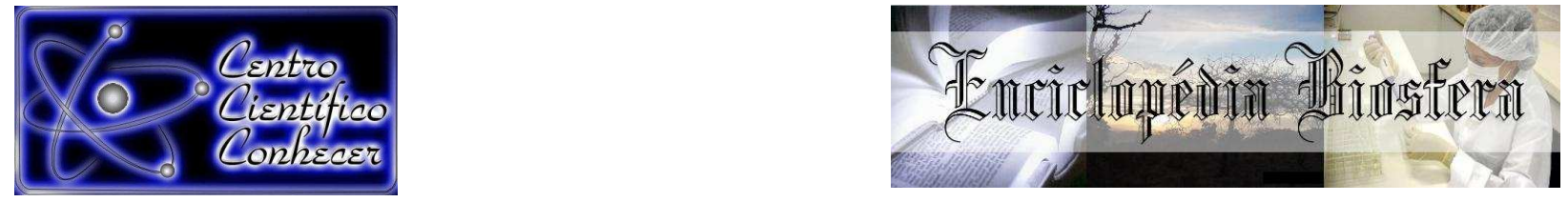

\title{
FENOLOGIA DE PRODUÇÃO E COMPORTAMENTO DE PREÇOS DA BERINJELA NO ESTADO DO CEARÁ
}

\author{
Antônio Moreira Barroso Neto ${ }^{1}$, Linda Brenna Ribeiro Araújo ${ }^{2}$, Alfredo Mendonça de \\ Sousa $^{3}$, Mário Rógerson de Abreu Vasconcelos ${ }^{4}$, Ervino Bleicher ${ }^{5}$ \\ 1 Engenheiro Agrônomo, mestrando em Fitotecnia, Universidade Federal do Ceará, \\ (ambnetonet@yahoo.com.br) Fortaleza - Brasil. \\ 2 Mestranda em Fitotecnia, Universidade Federal do Ceará. \\ 3 Mestrando em Solos e Nutrição de Plantas, Universidade Federal do Ceará. \\ 4 Graduando em Agronomia, Universidade Federal do Ceará. \\ 5 Doutor, Professor do Programa de Pós-Graduação em Fitotecnia, Universidade \\ Federal do Ceará.
}

Recebido em: 08/09/2015 - Aprovado em: 14/11/2015 - Publicado em: 01/12/2015

DOI: http://dx.doi.org/10.18677/Enciclopedia_Biosfera_2015_157

\begin{abstract}
RESUMO
A berinjela, uma das principais culturas olerícolas em cultivo no Brasil e no mundo, tem apresentado um aumento significativo tanto em consumo, como, consequentemente, em área de cultivo. O conhecimento da fenologia da cultura, assim como o conhecimento das características de mercado da mesma, possui grande importância no contexto de planejamento da produção e obtenção de melhores rendimentos econômicos. Assim, Objetivou-se calcular os graus-dia acumulados em diferentes estádios fenológicos no cultivo da berinjela, cultivar comprida roxa, no estado do Ceará e analisar a sazonalidade de preços da cultura. As avaliações foram realizadas conforme o seguinte ciclo fenológico: semeadura à segunda folha (V2), semeadura à quinta folha (V5), semeadura à décima folha (V10), semeadura ao primeiro botão floral (R1), semeadura à primeira flor (R2) e semeadura ao primeiro fruto (RF). Para a realização da análise de sazonalidade utilizou-se, a fim de determinar os índices estacionais de preços, o método da média aritmética móvel. Foram necessários 2487,26 graus-dia (87,24 dias) para inicio da frutificação. Observou-se que no mês de maio e no período de julho à dezembro ocorrem os maiores preços, correspondendo à períodos de entressafra. De acordo com o aspecto térmico, pode-se observar que a berinjela comprida roxa apresenta boa uniformidade, apresentando potencial para o cultivo de mais uma safra, em condições climáticas semelhantes às verificadas na região em estudo.
\end{abstract}

PALAVRAS - CHAVE: Fenofase, Grau-Dia, Sazonalidade, Solanum melongena

\section{PHENOLOGY PRODUCTION AND BEHAVIOR OF EGGPLANT PRICES CEARÁ STATE}

ABSTRACT
The eggplant, a major vegetable crops in cultivation in Brazil in the world has
presented a significant increase both in consumption and consequently in their
cultivation area. Knowledge of the phenology of culture, as well as knowledge of 
market characteristics thereof, has great importance in the planning context of production and achieve better economic returns. Thus aimed to calculate the accumulated degree-days in different growth stages on the cultivation of eggplant, purple grow long in the state of Ceará and analyze the seasonality of crop prices. The evaluations were performed as follows phenological cycle: sowing the second sheet (V2), sowing the fifth sheet (V5), sowing the tenth sheet (V10), sowing the first flower bud (R1), sowing to first flower (R2) and sowing the first fruit (RF). To carry out the seasonality analysis was used in order to determine the seasonal price indices, the method of the mobile arithmetic mean. It took 2487.26 degree days (87.24 days) to start fruiting. It was observed that in May and from July to December higher prices occur, corresponding to the periods of season. According to the thermal aspect, we can see that the long purple eggplant has good uniformity, with potential for more of a crop cultivation in climatic conditions similar to those seen in the region under study.

KEYWORDS: Phenophase, Degree-Day, Seasonality, Solanum melongena

\section{INTRODUÇÃO}

A berinjela, Solanum melongena (L.) é considerada uma importante cultura olerícola no Brasil e no mundo. Pertencente à família Solanaceae é mais adaptada às condições de clima tropical, embora possa ser cultivada, durante boa parte do ano, em regiões de clima subtropical (EMBRAPA, 2011).

Um aumento significativo no consumo dessa hortaliça tem ocorrido nos últimos anos, quando inúmeras pesquisas destacaram seu valor nutricional apontando altos teores de sais minerais, vitaminas e fibras. Neste cenário de demanda crescente, a produção da cultura mais que dobrou nos últimos 15 anos no Brasil (BRITO et al., 2012). Este crescimento ocasionou também aumentos nos preços, os quais vêm apresentando sazonalidade nos períodos de safra e entressafra, sendo influenciados, dentre outros fatores, por fatores relacionados ao clima.

Nos últimos anos, estudos vêm demonstrando a ocorrência de mudanças no clima mundial, mudanças essas que têm prejudicado a agricultura. De acordo com NOBRE et al. (2005), pequenas alterações como a elevação de $1^{\circ} \mathrm{C}$ na temperatura, provocam grandes perdas econômicas para muitas culturas, assim, deve-se ter cada vez mais controle sobre as condições fornecidas às plantas para se ter maiores rendimentos.

Nesse sentido, pesquisadores como PALARETTI et al. (2013) e FUKUNAGA et al. (2013) têm utilizado a soma térmica para o desenvolvimento de estádios das culturas como uma importante ferramenta no cultivo de hortaliças. O método de graus-dia baseia-se na premissa de que a planta necessita de certa quantidade de energia, representada pela soma térmica acima de uma temperatura base, para completar determinada fase fenológica ou mesmo o seu ciclo total (SOUZA et al., 2011). De maneira indireta, o método indica o desenvolvimento da planta em função da radiação solar disponível, que altera a temperatura do ar e participa do processo de fotossíntese (FUKUNAGA et al., 2013).

Segundo OLIVEIRA et al. (2012), essa técnica vem auxiliando produtores de diversas regiões no planejamento de plantio e colheita, da época de realização de tratos culturais e do uso de produtos fitossanitários, além de facilitar o zoneamento de espécies, mostrando as adaptações a determinados ambientes. Com as constantes mudanças climáticas, o cálculo dos graus-dia acumulados vem 
ganhando outras utilidades, reestabelecendo calendários agrícolas e reduzindo perdas nos cultivos.

Estas instabilidades climáticas afetam diretamente os preços dos produtos agrícolas através da oneração dos custos de produção, logo o conhecimento do comportamento dos preços dos produtos agrícolas no mercado se faz necessário para a obtenção de melhores rendimentos econômicos da produção. Esta ferramenta vem auxiliar na organização e planejamento do produtor rural, que aliada ao conhecimento do comportamento fenológico da cultura proporciona uma administração mais eficiente da produção agrícola (PINHEIRO et al, 2015).

Esta instabilidade climática preocupa produtores rurais, principalmente no estado do Ceará, onde este fator afeta significativamente a oferta dos produtos. DJAU et al. (2014), afirmam que em um cenário como este, conhecer o comportamento dos preços dos produtos comercializados, significa aumentar as chances de maiores receitas, pois possibilita ao produtor escolher períodos de alta de preços para vender seus produtos.

Para GONTIJO et al. (2011) e HARZER et al. (2012), o acesso a informação é uma questão de sobrevivência em mercados competitivos como o de produtos agrícolas, sendo o conhecimento das variáveis da produção (climáticas, agronômicas e de preços), imprescindível tanto para a programação, como para o planejamento e financiamento de cultivos. Nesse sentido, o objetivo deste trabalho foi calcular os graus-dia acumulados em diferentes estádios fenológicos da cultura da berinjela (cultivar comprida roxa) no estado do Ceará e analisar a sazonalidade de preços desta cultura.

\section{MATERIAL E MÉTODOS}

\section{Fenologia e Graus-dia}

O experimento foi conduzido no setor de horticultura pertencente ao Departamento de Fitotecnia do Centro de Ciências Agrárias da Universidade Federal do Ceará (UFC), em Fortaleza-CE, situado nas coordenadas de latitude 0346 S e longitude 38구 $\mathrm{W}$ com 27 metros de altitude. O período da análise foi de setembro a dezembro de 2010.

Utilizou-se para o ensaio a variedade comprida roxa. A semeadura foi realizada em bandejas de isopor contendo 128 células, semeando-se três sementes por célula, às quais foram preenchidas com um substrato composto de solo e esterco bovino na proporção volumétrica de $2: 1(\mathrm{v} / \mathrm{v})$. O desbaste foi realizado quando as mudas apresentaram duas folhas definitivas.

Após o estabelecimento das mudas com duas folhas por planta (30 dias após a emergência, em média), foram transplantadas 25 mudas para um canteiro de $1,0 \mathrm{x}$ $10,0 \mathrm{~m}$, os quais foram previamente preparados com $20 \mathrm{Kg}$ de esterco bovino por canteiro. O espaçamento utilizado foi de $60 \mathrm{~cm}$ entre linhas e $80 \mathrm{~cm}$ entre plantas. Os tratos culturais e fitossanitários realizados seguiram recomendações técnicas para cultura citados nos boletins técnicos da área.

Para o acompanhamento dos estádios fenológicos foram estabelecidas seis fases: semeadura à segunda folha (V2), semeadura à quinta folha (V5), semeadura à décima folha $(\mathrm{V} 10)$, semeadura ao primeiro botão floral $(\mathrm{R} 1)$, semeadura à primeira flor (R2) e semeadura ao primeiro fruto (RF). O método usado para o cálculo de unidade calórica foi o método do menor desvio padrão, em dias. Este método 
também é conhecido como método residual, apresentado por GLAUCO et al. (2011), segundo a Equação 1.

$U C=\Sigma[(T+t) / 2-t b]$

Em que,

UC - Unidades de Calor acumuladas;

$\mathrm{T}$ = temperatura máxima diária $\left({ }^{\circ} \mathrm{C}\right)$;

$\mathrm{t}$ = temperatura mínima diária $\left({ }^{\circ} \mathrm{C}\right)$;

tb $=$ temperatura base $\left({ }^{\circ} \mathrm{C}\right)$.

A temperatura base usada para o cálculo no ensaio com a cultura da berinjela, foi de $11^{\circ} \mathrm{C}$, conforme cita JOVANOVIC \& ANNANDALE (2000) para solanáceas. Foram coletados dados de temperaturas máxima e mínima diária, os quais foram obtidos na Estação Meteorológica do Centro Ciências Agrárias da Universidade Federal do Ceará, sendo estes dados utilizados para os cálculos de unidade calórica.

\section{Sazonalidade da cultura da berinjela}

Para a realização da análise de sazonalidade, foram utilizados os preços dos últimos 10 anos (2005 a 2014), coletados no site oficial da Central de Abastecimento do Ceará - CEASA-CE. Utilizou-se, a fim de determinar os índices estacionais de preços, o método da média aritmética móvel, exemplos da aplicação deste método podem ser encontrados em SANTANA (2003) e MENDES \& PADILHA JUNIOR (2007).

Inicialmente procedeu-se a deflação dos valores nominais (com inflação) para valores reais (sem inflação) utilizando-se a tabela de IGP-DI calculada pela FGV (base: dezembro de 2014). Definida a base a ser utilizada aplicou-se a seguinte fórmula para a obtenção dos preços reais:

\section{$P$. Real $=(I G P-D I$ do mês base $/ I G P-D I$ de outros meses $) * P$. Nominal}

Depois de realizada a deflação do histórico de preços, determinou-se as médias aritméticas móveis centradas em 12 meses. O procedimento para a determinação das médias aritméticas móveis foi realizado conforme a fórmula a seguir:

$M M C=\left(\Sigma^{6-i+6} P i\right) / 13$

Em que,

MMC = Média Móvel centralizada;

$\Sigma \mathrm{Pi}=$ Somatório do mês $i$ (mês analisado), os seis meses anteriores ao mês $i$ e os seis meses posteriores ao mês $i$;

Esta média apresenta a mesma tendência da série de preços original mostrando as flutuações cíclicas em torno da série de preços. Outra característica interessante à cerca da média aritmética móvel é que esta elimina as flutuações de curto prazo ou aleatórias que se apresentam na série de preços original.

A média móvel centralizada foi calculada para todos os meses a partir do mês de julho de 2005 até o mês de junho de 2014. Com as médias determinadas calculou-se o IEP (índice estacional de preço) através da seguinte fórmula: 
$I E P=\left(\frac{P}{M M C}\right) * 100$

Em que,

IEP = Índice estacional de Preço, em \%;

$\mathrm{P}=$ Preço no mês analisado, em $\mathrm{R} \$$;

$\mathrm{MMC}=$ Média Móvel Centralizada, em $\mathrm{R} \$$.

Após o cálculo do IEP, procedeu-se a determinação do índice sazonal. Para isso, calculou-se inicialmente o IEP médio para cada cultura considerando os 12 meses do ano (vale ressaltar que estes meses representam a média dos meses correspondentes para todo o período analisado), caso o valor da média calculada não seja igual a 100, cada índice mensal deve ser ajustado por meio da multiplicação por um fator de correção conveniente, definido através da seguinte equação:

Fator de Correção $=\left(\frac{100}{\text { IEPmếdio }}\right)$

Após o cálculo do fator de correção, procedeu-se a multiplicação deste com o IEP de cada mês, obtendo-se, assim, os índices de sazonalidade. Em sequência à determinação dos índices de sazonalidade, determinaram-se os limites superiores e inferiores de cada mês para todo o período analisado. Esses dados foram utilizados para a confecção de gráficos onde é possível verificar a variação dos índices sazonais para identificação de períodos de safras e entressafras.

\section{RESULTADOS E DISCUSSÃO}

\section{Fenologia e Graus-dia}

A temperatura máxima observada durante o experimento foi de $31,2{ }^{\circ} \mathrm{C}$ e a mínima, de $24^{\circ} \mathrm{C}$ (figura 1), valores estes similares aos de RIBEIRO (2007) e FILGUEIRA (2008), os quais comentam que o clima favorável para o desenvolvimento da berinjela encontra-se a uma temperatura média, durante o dia, variando de 25 a $35^{\circ} \mathrm{C}$, e durante o período noturno, variando de 20 a $27^{\circ} \mathrm{C}$, sendo esta cultura favorecida pelo calor.

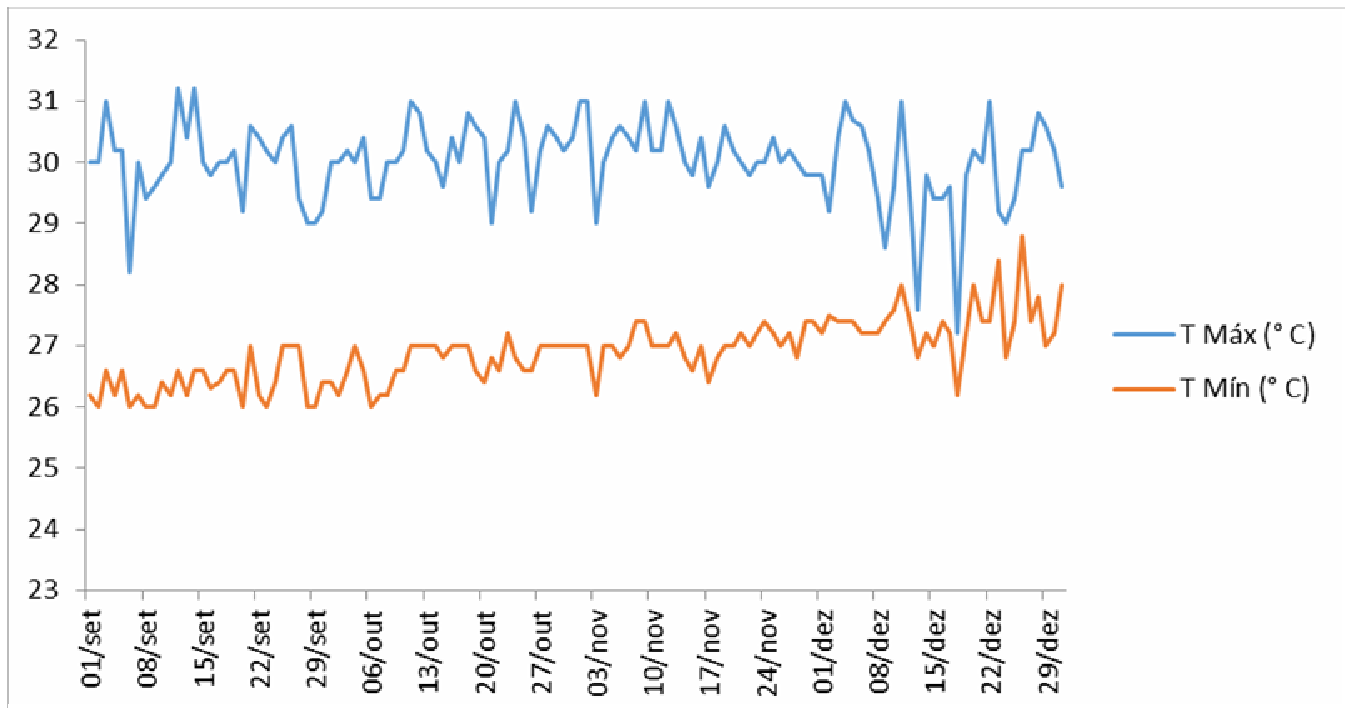

FIGURA 1 - Temperatura máxima e mínima no decorrer do experimento. 
Os resultados da caracterização fenológica da berinjela cv. comprida roxa podem ser observados na tabela 1. Observa-se que as plantas atingiram o estágio de duas folhas (V2) com 1015,05 Graus-Dia (GD), e 30,44 dias após a semeadura (DAS). Nesta fase o coeficiente de variação (CV\%) foi abaixo de cinco, fato este explicado por se tratar da fase de formação de mudas, na qual observou-se uma grande uniformidade em seu estabelecimento inicial. Para as fases V5 e V10, foram necessários 1535,56 graus-dia (45,40 dias) e 2009,78 graus-dia (67,28 dias), respectivamente. Quanto as fases R1, R2 e RF foram necessários 2059,42 GD (71,16 dias), 2211,99 GD (77,32 dias) e 2487,26 (87,24 dias), respectivamente.

Estes dados divergem de RIBEIRO (2007) que afirma que o período da colheita da berinjela comprida roxa ocorre entre 100-140 dias após a semeadura. No presente trabalho, o período de colheita foi atingido com menos de 100 dias, fato este explicado pela alta temperatura durante o período de análise e pouca oscilação da mesma, conforme relata GADIOLI et al. (2000) que a temperatura é um dos principais fatores que podem afetar a quantidade de energia metabólica do material genético, influenciando no ciclo.

Pelo observado, a berinjela comprida roxa apresentou um encurtamento do ciclo, fato este que pode contribuir para o aumento do número de ciclos de cultivo, auxiliando o produtor a obter uma maior rentabilidade, mediante programação dos cultivos, podendo fazê-la buscando lançar o produto em janelas de mercado no qual o preço esteja maior devido a baixa oferta do produto.

Segundo ROCHA (2009), o conhecimento da fenologia de uma cultura possui grande importância, tendo em vista que o sistema produtivo de uma cultura é complexo e resultado de uma série de fatores que são explicitados por respostas de curto e longo prazo de acordo com o potencial genético e fisiológico expresso em um determinado ambiente.

OLIVEIRA et al. (2009) trabalhando com o híbrido Ciça e variedade Beriló em Seropédica-RJ, obtiveram frutos com 77 e 91 dias, respectivamente. Por se tratarem de materiais genéticos precoces, há uma redução no ciclo. Mas comparando com o material em estudo no presente trabalho, a berinjela cv. comprida roxa, percebe-se uma semelhança nos dias para a colheita, fato este explicado pela condição climática da região de Fortaleza- $\mathrm{CE}$, que possui altas temperatura. 
TABELA 1- Número de dias e Graus-Dias acumulados para cada estádio de desenvolvimento da berinjela cv. comprida roxa

\begin{tabular}{|c|c|c|c|c|c|c|c|c|c|c|c|c|}
\hline \multirow{2}{*}{ Planta/Fase } & \multicolumn{2}{|c|}{ V2 } & \multicolumn{2}{|r|}{ V5 } & \multicolumn{2}{|c|}{ V10 } & \multicolumn{2}{|c|}{ R1 } & \multicolumn{2}{|c|}{$\mathbf{R 2}$} & \multicolumn{2}{|c|}{$\mathbf{R F}$} \\
\hline & DAS $^{*}$ & $U C^{* *}$ & DAS & UC & DAS & $\mathrm{UC}$ & DAS & $\mathrm{UC}$ & DAS & $\mathrm{UC}$ & DAS & UC \\
\hline 1 & 30 & 1000,65 & 41 & 1392,55 & 64 & 1822,85 & 72 & 2082,75 & 81 & 2344,75 & 102 & 3024,6 \\
\hline 2 & 30 & 1000,65 & 44 & 1491,45 & 69 & 1985,15 & 70 & 2017,85 & 77 & 2246,35 & 93 & 2766,1 \\
\hline 3 & 30 & 1000,65 & 46 & 1555,65 & 70 & 2017,85 & 74 & 2148,05 & 84 & 2353,75 & 109 & 3164,05 \\
\hline 4 & 30 & 1000,65 & 41 & 1392,55 & 64 & 1822,85 & 70 & 2017,85 & 72 & 2082,75 & 77 & 2016,95 \\
\hline 5 & 30 & 1000,65 & 42 & 1425,35 & 64 & 1822,85 & 72 & 2082,75 & 74 & 2148,05 & 88 & 2485,15 \\
\hline 6 & 30 & 1000,65 & 44 & 1491,45 & 66 & 1887,85 & 66 & 1887,85 & 68 & 1952,05 & 74 & 2148,05 \\
\hline 7 & 30 & 1000,65 & 43 & 1458,75 & 63 & 1789,65 & 72 & 2082,75 & 84 & 2353,75 & 90 & 2670 \\
\hline 8 & 30 & 1000,65 & 44 & 1491,45 & 66 & 1887,85 & 74 & 2148,05 & 77 & 2016,95 & 79 & 2081,85 \\
\hline 9 & 30 & 1000,65 & 44 & 1491,45 & 63 & 1789,65 & 66 & 1887,85 & 72 & 2082,75 & 77 & 2016,95 \\
\hline 10 & 30 & 1000 & 49 & 1654,35 & 77 & 2246,35 & 74 & 2148,05 & 86 & 2510,1 & 88 & 2485,15 \\
\hline 11 & $v$ & 1000,65 & 60 & 2015,95 & 82 & 2408,1 & 84 & 474,9 & 93 & 2766,1 & 112 & 3180,9 \\
\hline 12 & 30 & 1000,65 & 55 & 1850,75 & 77 & 2246,35 & 68 & 1952,05 & 74 & 2148,05 & 79 & 2081,85 \\
\hline 13 & 34 & 1131 & 55 & 1850,75 & 77 & 2246,35 & 72 & 2082,75 & 84 & 2474,9 & 93 & 2766,1 \\
\hline 14 & 30 & 1000,65 & 41 & 1392,55 & 61 & 2181,05 & 63 & 1789,65 & 66 & 1887,85 & 74 & 2148,05 \\
\hline 15 & 30 & 1000,65 & 42 & 1425,35 & 64 & 1822,85 & 74 & 2148,05 & 77 & 2016,95 & 97 & 2894,7 \\
\hline 16 & 30 & 1000,65 & 41 & 1392,55 & 55 & 1850,75 & 60 & 2015,95 & 63 & 1789,65 & 74 & 2148,05 \\
\hline 17 & 30 & 1000,65 & 41 & 1392,55 & 63 & 1789,65 & 66 & 1887,85 & 72 & 2082,75 & 79 & 2081,85 \\
\hline 18 & 30 & 1000,65 & 44 & 1491,45 & 69 & 1985,15 & 72 & 2082,75 & 74 & 2148,05 & 81 & 2344,75 \\
\hline 19 & 30 & 1000 & 44 & 1491,45 & 61 & 2181,05 & 63 & 1789,65 & 66 & 1887,85 & 74 & 2148,05 \\
\hline 20 & 30 & 1000 & 38 & 1262,75 & 49 & 1654,35 & 66 & 1887,85 & 72 & 2082,75 & 74 & 2148,05 \\
\hline 21 & 30 & 1000 & 48 & 1621,65 & 71 & 2050,45 & 74 & 2148,05 & 84 & 2353,75 & 84 & 2353,75 \\
\hline 22 & 30 & 1000 & 41 & 1392,55 & 61 & 2181, & 72 & 2082,75 & 74 & 2148,05 & 81 & 2344,75 \\
\hline 23 & 32 & 1066,65 & 46 & 1555,65 & 68 & 1952,05 & 77 & 2016,95 & 79 & 2081,85 & 84 & 2353,75 \\
\hline 24 & 30 & 1000,65 & 50 & 1687,25 & 81 & 2376,15 & 81 & 2376,15 & 90 & 2670 & 109 & 3164,05 \\
\hline 25 & 35 & 1164,05 & 51 & 1720,75 & 77 & 2246,35 & 77 & 2246,35 & 90 & 2670 & 109 & 3164,05 \\
\hline ÉDI & 30,44 & 1015,05 & 45,4 & 1535,56 & 67,28 & 2009,78 & 71,16 & 2059,42 & 77,32 & 2211,99 & 87,24 & 2487,26 \\
\hline DES & 1,27 & 41,43 & 5,22 & 172,99 & 7,78 & 207,61 & 5,48 & 159,05 & 7,86 & 252,66 & 12,35 & 404,28 \\
\hline CV\% & 4,16 & 4,08 & 11,5 & 11,27 & 11,57 & 10,33 & 7,7 & 7,72 & 10,16 & 11,42 & 14,15 & 16,25 \\
\hline
\end{tabular}

*DAS: Dias Após a Semeadura

** UC: Unidade Calórica em Grau-dia

Este conhecimento permitirá que produtores venham a planejar métodos racionais de cultivo, contribuindo para expressão do potencial produtivo das espécies vegetais cultivadas (FAYAD et al., 2001). Além disso, possibilitará a investigação do efeito dos fenômenos ecológicos sobre o crescimento, como a adaptabilidade das espécies em ecossistemas diversos, efeitos de competição, diferenças genotípicas da capacidade produtiva e influência das práticas agronômicas sobre o crescimento conforme cita ROCHA (2009).

Analisando o aspecto térmico, pode-se observar que a berinjela cv. comprida roxa apresenta boa uniformidade, com baixa variação na demanda térmica em cada fase de todas as 25 plantas em estudo. Isso revela o potencial para o cultivo de mais de uma safra, nas condições climáticas semelhantes às da região em estudo.

\section{Sazonalidade da cultura da berinjela}

Embasado nos resultados da avaliação fenológica, aquelas observações podem ser alinhadas com os estudos de mercado da berinjela no estado do Ceará, direcionando os melhores períodos para o cultivo, tanto no âmbito agronômico como econômico. 
A figura 2 a seguir apresenta o comportamento dos índices sazonais de preços, na qual é possível observar nítida flutuação ao longo do ano. Observa-se que no mês de maio e no período de julho à dezembro ocorrem os maiores preços, correspondendo à períodos de entressafra. Já no período de janeiro à abril e no mês de junho ocorre o período considerado de safra, em que os índices sazonais mantêm-se abaixo de 100.

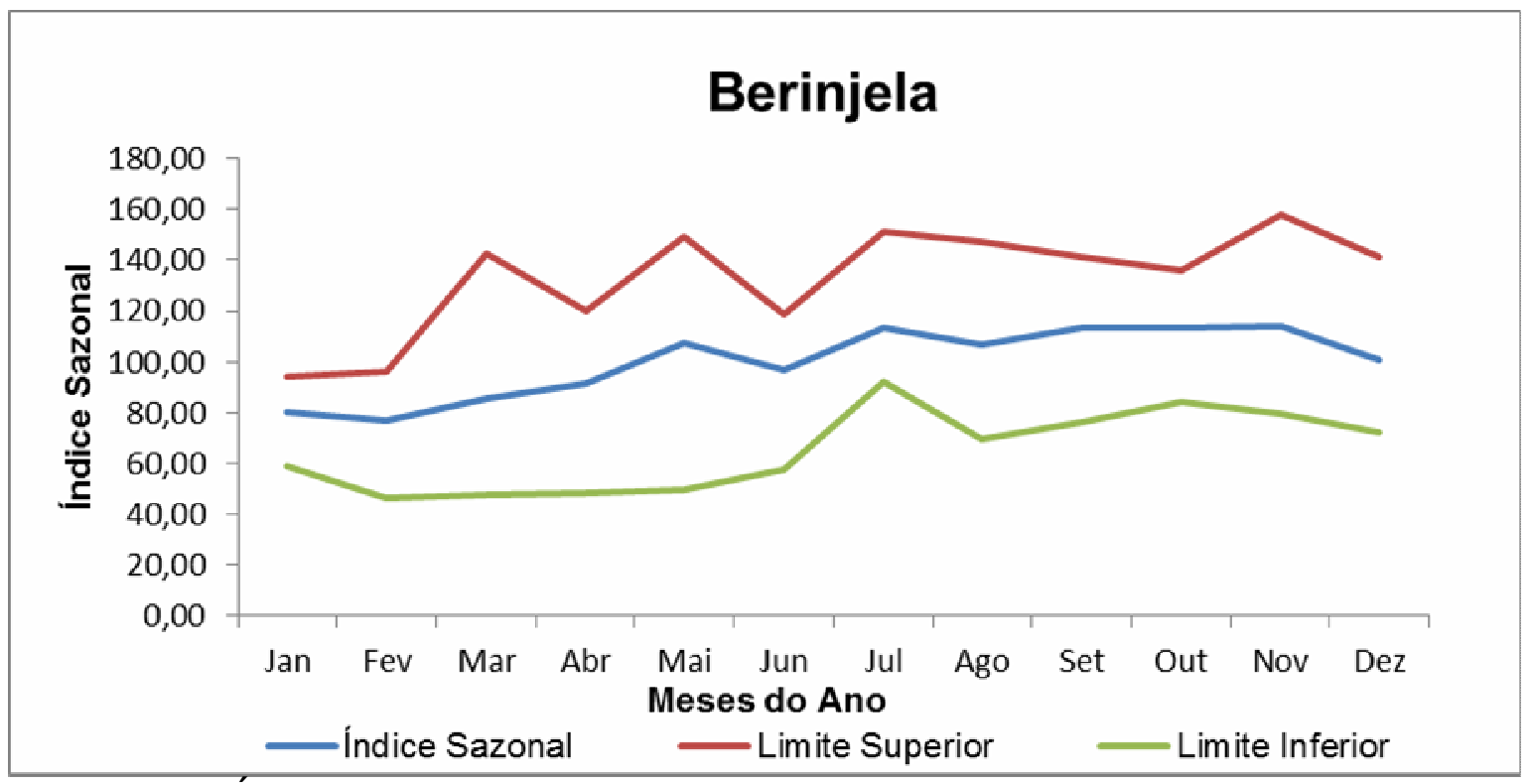

FIGURA 2 - Índices estacionais de Preços do feijão verde, na CEASA - CE.

Os dados de sazonalidade de preços mostram que os períodos mais propícios para se obter um melhor preço no mercado se encontra entre os meses de julho a dezembro, período de entressafra, no qual o produtor pode se programar para aproveitar esta janela de mercado, iniciando o cultivo no inicio de abril, uma vez que a cultura diminui o ciclo com as condições climáticas da região (no caso regiões com características climáticas semelhantes à região de estudo.

RIBEMBOIN (2015) cita que tais fatos são explicados porque as culturas dependem de fatores climáticos, como luminosidade e temperatura, sendo a perecibilidade, homogeneidade, sazonalidade de oferta, riscos climáticos, baixa elasticidade da demanda e rigidez de oferta características intrínsecas à produção agrícola e seus produtos que influenciam diretamente na rentabilidade do produtor.

Outro fator que pode explicar o comportamento sazonal no preço da berinjela no Ceará está na origem da produção agrícola do estado, havendo uma dependência da produção da serra da Ibiapaba, com pouca participação de outras regiões do estado e de outros estados da federação, segundo a CEASA (2015).

O comportamento supracitado corrobora com BENTO \& TELES (2013), os quais afirmam que a sazonalidade é reflexo direto da dependência de regiões produtoras, fatores climáticos e condicionantes biológicos (pragas e doenças) que limitam a produção em períodos específicos, assim como todos os segmentos do agronegócio, sendo entraves que limitam ou impedem a produção de determinadas culturas.

$\mathrm{Na}$ tabela 2 a seguir, pode-se observar uma análise de estatística descritiva considerando os índices sazonais de preços, limites inferiores e limites superiores. 
TABELA 2- Estatística descritiva (considerando: Índice sazonal, limite superior e limite inferior).

\begin{tabular}{cccccc}
\hline Meses & Limite Inferior & indice Sazonal & Limite Superior & Desvio Padrão & CV\% \\
\hline Jan & 59,09 & 80,46 & 93,88 & 17,55 & 7,52 \\
Fev & 46,32 & 76,9 & 95,93 & 25,03 & 11,42 \\
Mar & 47,97 & 85,31 & 142,58 & 47,65 & 17,27 \\
Abr & 48,58 & 91,45 & 119,79 & 35,85 & 13,8 \\
Mai & 49,73 & 107,47 & 149,31 & 50 & 16,31 \\
Jun & 57,69 & 96,86 & 118,75 & 30,94 & 11,32 \\
Jul & 92,36 & 113,13 & 151,53 & 30,02 & 8,41 \\
Ago & 69,83 & 106,51 & 147,44 & 38,83 & 11,99 \\
Set & 76,27 & 113,54 & 141,5 & 32,73 & 9,88 \\
Out & 84,17 & 113,69 & 136,09 & 26,04 & 7,8 \\
Nov & 79,33 & 113,96 & 157,63 & 39,24 & 11,18 \\
Dez & 71,98 & 100,72 & 141,56 & 34,96 & 11,13 \\
\hline
\end{tabular}

Observando a tabela 2, embasada pela análise do gráfico da figura 2, pode-se perceber uma mudança significativa no comportamento dos índices sazonais ao longo do ano. Estes índices mantêm-se em alta no período de entressafra, no mês de maio e no período de julho à dezembro, onde o pico ocorre no mês de novembro, cujo índice é de $113,96 \%$, e em baixa no período de safra da cultura, no período de janeiro à abril e no mês de junho, onde os índices tendem a diminuir, atingido o valor mínimo de $76,90 \%$ no mês de fevereiro. Os resultados comprovam a necessidade de ampliação das fronteiras de cultivos da berinjela no estado aproveitando os períodos de entressafra, períodos cujos resultados de produção são favoráveis devido ao maior preço de mercado, devendo ser os cultivos dotados de irrigação devido à ausência de chuvas nos meses de julho a dezembro.

Como citam GADIOLI et al. (2000), o conhecimento das exigências térmicas, desde a emergência ao ponto de maturidade fisiológica, é fundamental para a previsão da duração do ciclo da cultura em função do ambiente. Essas informações, associadas ao conhecimento da fenologia da cultura e ao comportamento dos preços da cultura no mercado, podem ser utilizadas no planejamento para a definição da época de semeadura, da utilização de insumos (fertilizantes, inseticidas, fungicidas e herbicidas, principalmente), da época de colheita e para o aproveitamento das janelas de mercado.

O alinhamento de tais informações apresenta-se com grande importância pelo fato do setor agrícola sofrer várias influências das mudanças na economia induzidas pela globalização, o que tem exigido maior eficiência técnica e econômica na condução dos cultivos. O conhecimento dos custos de produção e da rentabilidade das culturas é cada vez mais importante no processo de tomada de decisão dos agentes do agronegócio (RIBEIRO, 2007).

\section{CONCLUSÕES}

Os estádios fenológicos da berinjela podem ser previstos por meio de acompanhamento de escalas embasadas em somatórios térmicos diários, de acordo com as necessidades térmicas do material genético para se atingir a maturidade. 
Constatou-se que os meses de julho a dezembro se caracterizam como períodos de entressafra da berinjela, isto é, período de elevação de preços, sendo observado este comportamento em toda série histórica.

O conhecimento das variabilidades agronômicas e economias podem auxiliar o produtor a buscar novos arranjos produtivos e estratégicos para se destacar no mercado, além de auxiliar no planejamento da produção agrícola.

\section{REFERÊNCIAS}

BENTO, D. G. C.; TELES, F. L. A sazonalidade da produção agrícola e seus impactos na comercialização de insumos. Revista Científica do Centro de Ensino Superior Almeida Rodrigues. Rio Verde, FAR/ISEAR, Ano 1, nº 1, jan. 2013.

BRITO, M. E. B.;MELO, A. S.DUTRA, A. F.. Comportamento fisiológico de berinjela cultivada em ambiente protegido sob taxas de reposição hídrica. 2012. Trabalho de Conclusão de Curso (Graduação em Ciências Agrárias) Universidade Estadual da Paraíba.

CEASA-CE: Central de Abastecimento do Ceará. Disponível em: < http://www.ceasa-ce.com.br/ > Acesso em: 3 Ago. 2015.

DJAU, M. A.; REIS, J. N. P.; LIMA, P.V.P.S. Análise de variação de preços de frutas no estado do Ceará de 2007 a 2011. Enciclopédia Biosfera, v. 10, p. 3434-3446, 2014.

EMBRAPA. Doenças da berinjela no Brasil. Circular técnica 97. Brasília, DF. 2011

FAYAD, J. A.; FONTES, P. C. R; CARDOSO, A. A.; FINGER, L. F.; FERREIRA, F. A. Crescimento e produção do tomateiro cultivado sob condições de campo e de ambiente protegido. Horticultura Brasileira, v.19, 3: 232-237. 2001.

FILGUEIRA, F. A. R. Novo manual de olericultura: agrotecnologia moderna na produção e comercialização de hortaliças. 3. ed. Viçosa, MG: UFV, 2008. 402 p.

FUKUNAGA, L. A.; ESCOBEDO, J. F.; TERAMOTO, É. T.; DOS SANTOS, C. M., DA SILVA, M. B. P. Índice de área foliar e matéria seca total do pimentão em função de graus-dia ou do saldo par acumulado dentro e fora de ambiente protegido. In: ASADES 2013-XXXVI Reunión de Trabajo-Tucuman. 2013.

GADIOLI, J. L.; DOURADO-NETO, D.; GARCÍA, A. G.; BASANTA, M. V. Temperatura do ar, rendimento de grãos de milho e caracterização fenológica associada à soma calórica. Scientia Agricola, v.57, n.3, p.377-383, jul./set. 2000.

GONTIJO, T. S.; FERNANDES, E. A.; SARAIVA, M. B. Análise da volatilidade do retorno da commodity dendê: 1980-2008. Revista de Economia e Sociologia Rural. Brasília. v.49, n.4. p. 857-874. 2011.

HARZER, J. H.; COSTA, C. T.; SILVA, W. V.; SOUZA, A. Eficiência dos mercados futuros de commodities agrícolas aplicando-se o teste de cointegração. Revista de 
Administração da Universidade Federal de Santa Maria. Santa Maria. v. 5. n. 2. p. 336-353. 2012.

JOVANOVIC, N. Z.; ANNANDALE, J. G. Crop growth model parameters of 19 summer vegetable cultivars for use in mechanistic irrigation scheduling models. Water SA. v.26, p.67-76, 2000.

MENDES, J. T. G.; PADILHA JUNIOR, J. B. Análise de preços agropecuários. In: MENDES, J. T. G.; PADILHA JUNIOR, J. B. Agronegócio: uma abordagem econômica. São Paulo: Pearson Prentice Hallp, p. 249-274, 2007.

NOBRE, C. A.; ASSAD, E. D.; OYAMA, M. D. Mudança Ambiental no Brasil - O impacto do aquecimento global nos ecossistemas da Amazônia e na agricultura. Scientific American Brasil. № 12. Set-2005.

OLIVEIRA, A. D.; DE LIMA, M. E.; DE CARVALHO, D. F.; GOMES, D. P.; DE ALMEIDA, W. S. Graus-dias acumulados para a berinjela em Seropédica, RJ. In: XVI Congresso Brasileiro de Agrometeorologia, 22 a 25 de setembro, Belo Horizonte, 2009.

OLIVEIRA, A. S. DE.; NETO, A. J. S.; RIBEIRO, A.; RASCON, N. J. L.; RODY, Y. P.; ALMEIDA, A. Q. De. Determinação do tempo térmico para o desenvolvimento de mudas de eucalipto na fase de enraizamento. Revista Brasileira de Engenharia Agrícola e Ambiental, Campina Grande, v. 16, n. 11, p. 1223-1228, 2012.

PALARETTI, L. F.; MANTOVANI, E. C.; DA SILVA, D. J.; CECON, P. R. Soma térmica para o desenvolvimento dos estádios do tomateiro. DOI: 10.7127/rbai. v.6n300089. Revista Brasileira de Agricultura Irrigada-RBAl, v. 6, n. 3, 2013.

PINHEIRO, J.I.; DE SOUSA, A.M.; BARROSO NETO, A.M.; NOGUEIRA, D.B.; ARAUJO, L.B.R. Efeito da sazonalidade no preço do coco verde no mercado atacadista do Ceará no período 2002-2014. In: II Simpósio Brasileiro de Recursos Naturais do Semiárido - SBRNS, 27 a 29 de maio, Quixadá - Ceará, 2015.

RIBEIRO, C. S. C. Berinjela (Solanum melongena L.). Embrapa Hortaliças, Sistemas de Produção,3, Versão Eletrônica Nov/2007. Disponível em: $<$ http://sistemasdeproducao.cnptia.embrapa.br/FontesHTML/Beringela/Beringela_Sol anum_melongena_L/index.html> Acesso em: 3 Ago. 2015.

RIBEMBOIN, J. A. Produtos Agrícolas e mercados no agronegócio. In: CALLADO, Antonio André Cunha (org). Agronegócio. São Paulo: Ed. Atlas, 2015. p.29-43.

ROCHA, M. Q. Crescimento, fenologia e rendimento do tomateiro cereja em cultivo hidropônico. 2009. 129 f. Dissertação (Mestrado em Agricultura familiar) Universidade Federal de Pelotas, Pelotas, 2009. 
SANTANA, A. C. Métodos quantitativos em economia: elementos e aplicações. 1. ed. Belém: UFRA,485 p, 2003.

SOUZA, A. P.; RAMOS, C. M. C.; LIMA, A. D.; FLORENTINO, H. O.; ESCOBEDO, J. F. Comparison of methodologies for degree-day estimation using numerical methods. Acta Scientiarum Agronomy. v. 33, n. 3, p. 391-400, 2011. 